\title{
Qualitative Analysis of Collaborative Learning Groups in Large Enrollment Introductory Astronomy
}

\author{
Chija Skala, Timothy F. Slater and Jeffrey P. Adams \\ Department of Physics, Montana State University, \\ Bozeman, MT 59717-3840, USA \\ skala@physics.montana.edu, slater@physics.montana.edu, \\ adams@physics.montana.edu
}

Received 1999 August 25, accepted 2000 May 2

\begin{abstract}
Large-lecture introductory astronomy courses for undergraduate, non-science majors present numerous problems for faculty. As part of a systematic effort to improve the course learning environment, a series of small-group, collaborative learning activities were implemented in an otherwise conventional lecture astronomy survey course. These activities were used once each week during the regularly scheduled lecture period. After eight weeks, ten focus group interviews were conducted to qualitatively assess the impact and dynamics of these small group learning activities. Overall, the data strongly suggest that students enjoy participating in the in-class learning activities in learning teams of three to four students. These students firmly believe that they are learning more than they would from lectures alone. Inductive analysis of the transcripts revealed five major themes prevalent among the students' perspectives: (1) self-formed, cooperative group composition and formation should be more regulated by the instructor; (2) team members' assigned rolls should be less formally structured by the instructors; (3) cooperative groups helped in learning the course content; (4) time constraints on lectures and activities need to be more carefully aligned; and (5) gender issues can exist within the groups. These themes serve as a guide for instructors who are developing instructional interventions for large lecture courses.
\end{abstract}

Keywords: astronomy education—collaborative group learning—research in teaching and learning

\section{Introductory Astronomy for Undergraduates in the USA}

Each year, more than 200,000 undergraduates enroll in introductory astronomy at colleges and universities in the USA (Fraknoi 1996). Like many other survey courses in the sciences, astronomy is offered at most institutions as a service course for many self-proclaimed apathetic and disinterested students fulfilling natural science distribution requirements (Zeilik et al. 1997). The most common student complaint is that the astronomy lecture material is irrelevant and unrelated to their undergraduate majors (Dennis 1990). This truism might actually be correct. When a science course is presented only as a long list of facts to be committed to short-term memory for the next multiple-choice test, the information is quickly forgotten and the course certainly is irrelevant to most academic majors. Yet, for this enormous population of college students, many of which are pre-service education majors, it is critical to 'get this course right'. Like many other introductory survey courses, this course often represents the last science course that many of these students will ever have. As such, these courses often serve as the final foundation for science concepts and attitudes towards science that graduates carry into everyday life.

It is generally recognised that a large-lecture learning environment can be improved substantially by moving learners from a passive role to a more active role. Attention demanding demonstrations and eloquent use of multimedia have always been a part of the talented introductory instructor's repertoire. However, effective active-learning requires students to do more than watch a presentation (Duncan 1999). For example, Mazur (1997) drastically improved student achievement by developing a series of ConcepTest questions for his Harvard physics students to tackle in learning teams in the context of lecture. Sokoloff \& Thornton (1997) discovered that physics students had significant test improvement using interactive lecture demonstrations strategies that require students to commit to their predictions. Mestre (1993) found that asking students to pose problems from a given scenario was an excellent tool for actively engaging students' thought processes. At the University of Washington, McDermott (1991) and her colleagues discovered that a highly-structured, guided inquiry approach based on student misconceptions research has enormous effects on student learning. Francis, Adams \& Noonan (1998) found that the University of Washington-style tutorials helped students retain knowledge for more than three years after their physics course. Compounding the evidence for active student involvement, Astwood \& Slater (1997) argued that students who actively complete assessment portfolios devote more time to the study of geology material than do students who do not compose portfolios and only passively listen to lectures (Slater 1997). Uniformly, the literature confirms that active learning strategies improve student performance.

The obstacle to providing 'easy to implement' inquiry-based learning activities and alternative assessments for students in large-enrollment courses is indeed formidable (Safko 1988; Zollman 1990; Slater \& Astwood 1995), but is not insurmountable. Zeilik (1997) has had significant success removing gender and ethnic- 
background examination performance differences by including specialised collaborative group activities within the context of astronomy courses. It was the original work by Zeilik and others that motivated the implementation and the subsequent qualitative evaluation of the project described here.

The effectiveness of collaborative learning groups is well-documented. According to Robert Slavin (1991), cooperative learning methods are among the most extensively evaluated alternatives to traditional instruction. In 1990, Slavin synthesised 67 high-quality, two-group comparison studies on student achievement in elementary and secondary schools. In his meta-analysis, he found $41(61 \%)$ of the studies found significantly greater achievement in cooperative classes than in control classes. Twenty-five $(37 \%)$ of the studies found no statistically significant differences and in only one study did the control group outperform the cooperative learning class. These studies did vary considerably on how cooperative learning was designed. However, when cooperative group instruction emphasised group goals and individual accountability (i.e. if learning groups earn rewards if all learners achieve higher levels of performance on individual measures), 37 out of 44 such studies $(84 \%)$ showed statistically significant positive achievement effects. In fact, taken collectively, research conducted by Slavin and others consistently shows that, using experimental/control comparisons of at least four weeks' duration, cooperative learning groups demonstrate positive outcomes in measures of achievement, self-esteem, intergroup relations, acceptance of academically handicapped students, attitudes toward school, and/or ability to work cooperatively.

Slavin (1991) suggested that why cooperative learning tasks are assigned is as important as the need for group goals and individual accountability. He convincingly advanced that this is because high-ability students working in a group to complete a worksheet have little reason to take the time to consult their less able teammates. In contrast, cooperative learning strategies appear to work much better when the group's task is to ensure that every group member learns something. This perspective provides rationale for every group member to explain concepts to teammates-a group achievement goal. Although common lore often reports that cooperative learning holds back high achievers, Slavin (1991) stated that the research literature provides absolutely no support for this claim.

\section{Context of the Study}

The typical nature of the large enrollment astronomy lecture is conducive to students playing the role of passive learners. The conventional student model is that students attend class (sometimes), copy notes from what the instructor places on the overhead screen, and reviews these notes before an examination. In this model, if a student misses a class, their perceived responsibility is to get the lecture notes from another student and review them before the next examination.

As part of a systematic effort to increase the studentactivity level in the classroom, the authors implemented series of small-group, collaborative learning activities in an otherwise conventional lecture astronomy survey course. The project was conducted at Montana State University in the introductory astronomy survey course for non-science majors with more than 200 students in each course section. These student-centred learning activities take 20-30 minutes to complete and are inserted once each week during the regularly scheduled lecture period. The activity titles are listed in Table 1 (Adams \& Slater 1998). The activities were unannounced and required students to work in self-formed groups of three to four students. The class met three times each week for 50 minutes in a multimedia lecture theatre with seats permanently fixed to the floor.

Table 1. Collaborative group learning activities for introductory astronomy

Designing an observatory
Lenses and telescopes
Star charts
Trigonometric parallax
Stellar spectra classification
HR diagrams
Spectroscopic parallax
Stellar evolution
Galaxy classification
Hubble's Law
Distances to the Moon and Sun
Tracing epicycles
Determining the orbit of Mars
The phases of Venus
Mapping the Solar System from Earth
Moon phases

As an example, consider the activity titled 'Designing an observatory'. Students are given a scenario in which they have been awarded a \$US6,000 grant from a telescope company to conduct astronomy public outreach through the local museum. The students must come to a group consensus and produce a justified list of materials for purchase. The students are given a current catalog and have 30 minutes to develop their wish list among reflecting telescopes, refracting telescopes, eyepieces, mounts, and binoculars. This activity truly represents an 'open-ended activity'. In other words, it has multiple entry points and multiple correct answers. Experience dictates that professional astronomers and undergraduate novices can both have meaningful discussions about how to outfit a local observatory albeit at very different levels of sophistication. Besides role playing activities such as this observatory design 
activity, other activities include historical reproductions of measurements, conceptual development activities, and science process skill activities.

In an effort to capitalise on existing collaborative learning groups, the authors also implemented group tests in addition to individual tests. In practice, students took a 20 item multiple-choice examination individually over a 30-minute period. After students submitted their examination, they received a second copy of the examination, identical to the first. This time, however, the students were allowed to discuss the examination questions with their collaborative learning group teammates. After discussion, each student handed in his or her own second examination. The scores from the first exam (done individually) and the second exam (done with discussion) were averaged together. The reason that each student submitted their own examination was that the groups were not required to reach a consensus. In other words, students answered their own test questions after group discussion and they might or might not have agreed with the group's majority opinion. This group testing had the additional benefit of demonstrating to the students once again that the instructors valued the collaborative learning groups.

\section{Description of Focus Groups}

For this project, focus group interviews were conducted to explore the hypothesis that the cooperative learning groups help students learn. Focus groups are unique in that they 'foster a group dialogue' which participants are free to discuss and debate in ways that are not possible in individual interviews. Focus groups have been used successfully in a variety of similar studies (Slater, Carpenter \& Safko 1996; Astwood \& Slater 1995; Rischbieter, Ryan \& Carpenter 1993; Cox \& Carpenter 1991; amongst many others). Hence, focus groups have the ability to obtain many ideas and/or issues that are of importance to the participants in a short period of time: from 30 minutes to 2 hours. Modern focus groups, or in depth group interviews, often consist of 8 to 12 participants and a single moderator. In the optimum scenario, participants represent a reasonable cross section of the population that the researcher(s) would like to evaluate (Morgan 1988). The role of the moderator is to present questions for the participants to discuss and to keep the discussion on the topic of interest of the researcher(s). The moderator is not allowed to participate in the discussion in any way for this may ultimately alter the data. The moderator may, however, ask more specific questions relating to the topic at hand in an effort to obtain more specific data. This does not allow the participants to discuss among themselves as much as would naturally happen. It does, however, yield data on a very specific subject in a short time.

Most focus group interviews are audio or videotape recorded, although a scribe can be present to record the conversations among the participants (Stewart \& Shamdasani 1990). The raw data obtained by any focus group are the dialogue among the participants. The researchers then analyse this dialogue using a strategy known as inductive analysis. By repeatedly reading the transcripts, the researchers identify themes that occur within the dialogues. They then assess the importance and relevance of each theme. This procedure might appear easier than it really is. Certain issues may arise within a discussion and all may be of equal importance to the participants, but because the majority of the participants agree on an issue, the issue may be mentioned several times but never be discussed. On the other hand, an issue might arise of equal importance to the participants, but because there is a debate about the affects of this issue, more time is usually devoted to discussing the particular issue. It would be very easy for the researchers to say the issue(s) that are discussed by the group the longest, or most in depth is of more importance to the participants than an issue not discussed. This may not be the case, it is very important that the researchers realise what the participants mean when they say the things they do. As such, focus groups are among the most popular type of qualitative research tools available in science education.

\section{Procedure}

For this project, the focus groups were conducted to explore the hypothesis that the cooperative learning groups were serving their purpose in helping students learn. Three astronomy education specialists aided the instructors by conducting the focus groups. These focus groups were held about eight weeks into the 16-week semester. Several recurring themes emerged through these focus groups including gender issues, attendance, and group learning verses lecture learning.

Students were asked to volunteer their time, about 90 minutes in the afternoon, to discuss the cooperative learning groups. As an incentive, the instructors offered 'upgrade coupons' to improve scores on a group activity to entice enough students to participate in the focus groups. This strategy worked exceedingly well as more than a third of the students participated. In fact one student reported going to the Introductory Astronomy class in the morning, went skiing during the day and made it back to school in time for his 3:00 focus group appointment. This method of enticing students to participate in a extracurricular activity by offering a 'free grade' initially appears to work well, but because these focus groups were anonymous, it is unclear exactly which types of students participated in these focus group sessions. Thus it is important to note that the data that were received by the focus groups might not represent a true cross section along ability levels due to the recruiting processes.

The students who volunteered to participate in the focus groups were randomly split up into ten groups: three all-male groups, four all-female groups and three mixed-gender groups. There were approximately eight students in each group. Each focus group was conducted 
Table 2. Exploration focus group script for collaborative groups in astronomy

Introduction: Hi. My name is and I am visiting Bozeman from The reason that we are conducting these group interviews is that those of us involved in this project, which includes your instructors, are interested in learning more about what is going on in this class from the students' perspective. The information that is gathered from these interviews will be used to make further course improvements. Specifically I want us to talk about the small group learning activities. What you think about them, what you like about them, and what you don't like about them. Most importantly, I want you to talk to each other instead of to me.

It is important that you know that none of your comments will be shared directly with your instructors. I plan to tape record the interview so that we can review your comments but your instructors will not listen to these tapes until after the end of the semester. Any comments that you make will be reported anonymously. I hope that this will make you feel free to answer my questions openly and honestly. If you are not comfortable with any aspect of this, you are free to leave and you may keep your 'upgrade coupon.' If there are no questions, we will begin.

(1) Why did you decide to take this particular class? [if no one volunteers-What have you heard about this class from other students?]

(2) One of the differences between this class and many others is the use of learning group activities. This is something that I would like to explore further. Could you please describe how you came to get in the learning group that you are working with now? [if no one volunteers-Tell me about the people in your group, are they friends or people that you met in class?]

(3) One of the things that your instructors have done is to assign specific roles within the group for each activity. How does your group REALLY work? [if no one volunteers-Tell me about who does what in your group and how that relates to the titles you sign your name next to.]

(4) How do you feel that the use of these group activities has affected your learning of astronomy? [if no one volunteersTell me about how this class compares to other classes you are taking right now]

(5) Is there anything that your instructors need to know as they make revisions to the class?

in a separate room. The reason for the different gender compositions of the focus groups was an attempt to pick up on any differences between the groups to hopefully identify any gender issues or problems within the learning groups.

The same interview script was used for each focus group regardless of the gender composition of the group and is shown in Table 2. It was explained to the participating students that the reason the focus groups were being conducted was because the people who were involved in this project, which included the instructors, were interested in what was going on in the classroom from the students standpoint. The students were also told that their comments would not be shared directly with their professors. The participants were made aware that the interview would be tape-recorded and transcribed to keep the anonymity of the participating students. The students were also informed that if they felt uncomfortable for any reason, they were allowed to leave the focus group and keep their upgrade coupon. It was further explained that the information obtained by these groups would be used for future course improvements.

\section{Results}

After analysing the transcripts from the ten studentfocus groups, five themes emerged:

(1) Cooperative group formation and composition needs to be more regulated.

(2) Assigned roles in cooperative groups should be less structured.

(3) Cooperative groups helped students learn.
(4) Time constraints on lecture and activities should be balanced.

(5) Gender issues exist within some groups.

Each theme emerged within every focus group, regardless of gender composition with the exception of the last theme. Theme (5) emerged as a topic of discussion in at least one of every group composition, but not all groups. It is important to note that these themes appeared without any conscious prompting by the moderators. Each group was asked the same initial series of discussion questions and moderators were allowed to pursue additional questions in order to gain more specific data. This flexible approach provided important insight on how students learn and work in their cooperative groups.

\subsection{Theme 1: Group Formation needs to be More Regulated}

It was important to the instructors that the groups are formed on the first day of class for two main reasons: to establish the tone for the course and to gain continuity within the groups. The groups were to self-form. The class members were instructed to pair-up with the person next to them. Then pairs of students were instructed to find another pair to work with, creating groups of four. Because these instructions were somewhat ambiguous, and the main purpose was to find a group of four to work with, three principal types of groups formed: random, familiar and mixed. In practice, an exact classification scheme proves to be problematic given the transient nature of the students-relatively high levels of absence, tardiness, and entrance to the class several weeks into the semester. 
Most commonly, the 'random' groups were composed of students who formed a group based on proximity. Several of these random groups were composed of the students who entered the class late. The important characteristic of members in random groups were that the students did not know each other prior to forming the group. The second type of group, 'familiar groups', were composed of students who knew each other prior to entering the class. Familiar groups seemed to be the most rare of the three groups observed. The students who composed the familiar groups could have been sitting in close proximity to each other, but this is not always the case. There were instances where students on one side of the room joined students on the other in order to work together. The most commonly formed groups were 'mixed groups'. Usually mixed groups consist of a pair of friends and two other random students from the class.

It was the instructor's intent to keep the same groups the entire semester, but because the groups had to be formed in an expeditious matter based mainly on proximity, and along with other extraneous influences, such as poor class attendance, a number of groups change members frequently during the semester. The instructors were aware of the situation, and allowed group switching to take place.

Many students reported that they preferred the way the groups were established rather than having been assigned cooperative groups by the instructors. One student remarked,

"I like this way better because you at least feel like you want to be there instead of you're forced to be there. I've always hated to be told, 'You are four, and that is your group.' It reminds me of high school."

Many students also reported that they attend class more frequently due to the cooperative nature of group learning:

'It definitely does make me go to class more cause I kind-of skip every once in a while. The learning activities is a motivator, ... the fact that it is fun ... It's not like you have to sit by yourself and listen to a professor go on and on, it is interesting and I learned a lot better.'

The relatively few negative comments voiced relating to group formation criticised the limited time allotted for self-formation.

Each type of cooperative group repeatedly demonstrated a common set of characteristics. The random style groups often lacked focus, cohesiveness and productivity. This appears to be due to three reasons: high absentee rate, conflicting motivations and personality conflicts. A high absent rate among the students in this group is likely the main factor as to why this type of group does not work well. For a group to function correctly, one of the prerequisites is to have all the group members present all the time. Many of these students failed to attend class and consequently missed group activities. Two students reported they were not able to name students in their cooperative groups. Another student reported that he would not be able to identify visually a member of his group if he was asked to do so. A student expressed her frustration as:

'We've got one guy, I don't know his name cause he's rarely
even there . . . which kind of hurts the group. . . . We haven't
seen him for three weeks and then he shows up for the [group]
test and then expects to take it.'

This is consistent with results recently reported by Wills (1999) and others.

The second difficulty that random groups often face is conflicting motivations among group members. There was often lack of respect of other group members' thoughts, opinions and feeling-apparently resulting from some students' desire to finish activities quickly and leave class early. When random groups do not function well, the primary cause is personality differences. The instructors realise that self-formed groups do not adequately engender groups suited for every student; accordingly, students are allowed to switch groups with the consent of an instructor.

Among the three types of cooperative groups, 'familiar groups' appear to be the most conducive to group learning. Unfortunately, familiar groups are also the least numerous. There were no complaints about group learning techniques or group members from any member in a familiar group. Students in a familiar group universally reported working well together. In addition to working well together in class, students in the familiar group were a support group for each other outside of class. If, for instance, one member of the group happened to miss a class, the other members would relay the information covered in that class to the absentee. Familiar groups also function outside of class as a study group before examinations. There were no reports of a familiar group switching members.

'Mixed groups' possess many of the advantages that are characteristic of the familiar groups, but they also are burdened by a few of the disadvantages common to the random groups. In many ways, mixed groups performed identically to the familiar groups but lacked any outside-of-class communication. Conflicting interests among group members was present, although it did not appear to affect cooperative group learning to the extreme that it seemed to in the random groups.

Poor attendance continues to be bothersome within the mixed groups. Groups of two and three formed inadvertently due to the continual absence of a member, or members, of certain cooperative groups. Some groups worked well without the presence of the fourth member, others felt deserted as seen in the following comments made by students:

'There's me and my friend and the other two guys rarely show up to do their part. So we get everything done. One of them was here the first day but he felt bad cause he didn't really understand what we were doing, and we haven't seen him much since. It's extremely hard that way cause we are responsible for doing the whole group.' 


\subsection{Theme 2: Groups need to be Less Internally Structured by Instructors}

The group activities were highly structured by preassigned roles. Each person was assigned a rotating role within his or her cooperative groups as leader, recorder, explorer, or skeptic. The purpose of this is two fold. First it was the instructor's wish to have every student actively participate in the group activities. The second goal of this strategy was to expose students to various roles scientists assume.

The group leader is responsible for initiating the discussion and maintaining the group's focus. The explorer's job is to generate new ideas and try to expand the group's focus. The skeptic listens carefully to the arguments made by others in the group to look for weaknesses or inconsistencies. As well as contributing to the general discussion, the recorder is responsible for writing the group's consensus report to be submitted for grading. A detailed explanation of the roles is given the students on the first day of class, both verbally and in writing. Yet, even with a verbal and written explanation, students universally reported that they did not follow the roles, much less understand the function of each role.

Students reported that they did not feel that the roles were necessary for their group to be productive. The following comment is representative of the general student viewpoint:

'I guess no one fights over what they want to do. Everyone just takes a job and does it. We don't really have a leader. I'd say, one of the girls is more skeptical than the others and we have one that's in the middle that's really quiet. I think the same work gets done either way.'

The only role that was consistently utilised and rotated by every group was the role of recorder. About half of the cooperative groups formally utilised the role of the leader and most groups did not use the roles of skeptic and explorer. Many students who participated in the focus groups did not even know the difference between those two roles.

Other than not knowing what the duty of the four roles were, three main reasons emerge as to why the students do not use assigned roles in their respective cooperative groups: poor class attendance, time constraints and personalities dominate over assigned roles. Poor attendance drastically hindered the consistent use of roles. Many groups had only three members due to a member who was habitually absent. Hence all four roles could not be adequately played. The two roles sacrificed by the vast majority of the groups are explorer and skeptic. Time constraints are also an important factor. Students reported that utilising the roles required more time than was allotted for the activity. Students argued that if they assumed their 'natural roles' that the group activities run smoother and faster. A student in a focus group defended this by saying:

'I think those [the assigned roles] are natural roles. Somebody can't be a leader if they're not, if they don't have leader abilities. I mean, if someone wants to write they should write, or if someone wants to lead and that's natural for them to be the leader, then they should.'

To partially validate these results, a survey was given at the end of the semester to assess how students felt about the cooperative learning groups and the internal structure of the groups. All of the data corresponded to the data received by the focus groups performed at mid-semester, except for the students' opinions about the assigned roles. At mid semester, the students who participated in the focus groups reported that almost none of the groups used the assigned roles. By the end of the semester $50 \%$, of the students reported on the survey that they were conformable with the roles and no change was necessary. It is unclear as to what changed the way students viewed the assigned roles. One hypothesis is that the students felt that they had more of an impact on the structure of the course at the time the focus groups were held due to the fact they were held mid-semester rather than at the end. After the focus groups were held and preliminary information was relayed back to the instructors via the moderators, the instructors reminded the class about the use of the roles and how important it was to use them. After reminding the students to use the roles, perhaps the students tried to use the assigned roles, and discovered it worked. This hypothesis cannot be supported by the present data, but merits additional investigation in future studies.

\subsection{Theme 3: Cooperative Groups support the Learning Process}

This may be the only area where there exists a complete consensus on a theme. Every student reported that they believed they learned the course material better through the aid of the cooperative learning groups. Many students claimed to learn more effectively when engaged in hands-on activities. Other students reported that the act of discussing the material with their peers solidified the concepts in their memories:

\footnotetext{
'It's just that we discuss it and if there's one person who doesn't understand then they don't have to they to explain it to themselves. You can also understand it more when you're trying to explain it to somebody else or. ... I really feel like I understand it better because of this class.' . . . 'I think it helps. It helps you to learn to listen to others' ideas and incorporate them into your thinking. . . It helps because you learn to write it out and talk to each other. It helps you absorb it a little bit better than if you did it on your own.'
}

This claim cannot be independently verified by a twogroup comparison study at the present time. In the next year, the Astronomy Diagnostics Test, developed by Slater, Hufnagel \& Adams (1999) will be available to compare student achievement in this course with other similar courses.

\subsection{Theme 4: Balance of Time allocated to Lecture and Group Activities}

Although the authors observed that few groups are still working on activities during the final three minutes of 
class, students in both the focus group interviews and in the follow-up survey stated that there was not enough time allotted to adequately complete the activities. Interestingly, the groups that were most vocal about the time issues were usually groups who did not work well together, mainly the random and mixed groups. The familiar groups typically reported sufficient time to complete the activities. This raises an intriguing question: Should additional class time be made available to the students in order to complete the activities, hence eliminating additional lecture time? A possible solution may be to shorten the group activities. If so, would abbreviating the group activities result in students believing that they have not learned the concepts as well as they are currently reporting? This issue is indeed worthy of additional investigation in the future.

\subsection{Theme 5: Extant Gender Issues in Some Cooperative Groups}

The initial motivation for this qualitative study was to uncover any gender issues that might occur when implementing collaborative learning groups. In other words, the issue most closely focused on was gender for this study. However, to the authors' surprise and delight, any serious problems related to gender that occurred within the groups were apparently absent. There seems to be no obvious correlation between gender and opinion of the cooperative groups, or with how they are structured when viewed through focus group interview transcripts. Occurring once in each type of focus groups, students suggested that male personalities could overpower female personalities in the cooperative learning groups. In a mixed gender focus group, a female stated that she did not always feel females had an equal voice in their cooperative groups. A male replied that the females were too passive. A representative comment was:

"There's three guys in the group and then there's me and I'm a girl. One of the guys for the longest time really talked down to me and they'd work a problem and I'd put my input in and he'd look at me and say, 'And do you understand'?"

Although it appears that there are not serious issues in the majority of groups, observations of group dynamics, reported elsewhere, might provide more insight into the prevalence of these important issues that are only briefly glimpsed in focus group interviews (Adams et al. 2000).

\section{Discussion}

The analysis of the focus groups transcript suggest that the cooperative learning groups are effective at assisting students in processing and learning the course material. There are some factors, however, that hinder how efficiently this instructional strategy operates in the large enrollment course for non-science majors. Clearly, the most important factor, apparent in four out of five themes, was poor attendance. The lack of attendance of students inhibits how well the cooperative learning groups work in numerous aspects: group formation, use of roles, and how effectively the groups aided in the learning processes of the participants to name a few. The unfortunate reality is that large universities often encounter poor attendance within large general science classes. The question arises then as to should emphasis be placed upon the students who are always present and let the others fall by the wayside? Or, alternatively, should the instructor focus on the students who rarely show up to class, and find ways to entice them to attend more often? Regardless, the regular use of cooperative learning groups and the placement of a substantial weight of the group activities as a part of the final grade, students are enticed to attend class more often than normal. Moreover, using the group activities further supports students in gaining a deeper understanding of the subject material.

A substantial conflict occurs when students with two extreme types of motivation are placed in the same cooperative learning group. This is a result of the process of self-formed groups that produces varying group compositions, some of which do not work well together. It is clear that the way the self-formed cooperative groups are created has room for improvement and needs to be systematically explored in future studies.

One option is to form temporary groups for the first three weeks, then form permanent groups afterward. It could be forewarned to the class that permanent groups would be formed so the students will keep this idea in the back of their mind while working in the temporary groups. By establishing temporary groups for the first few weeks in the semester, the instructors would still establish the tone for the course at the beginning of the semester. This method also eliminates the cooperative groups consisting of students who enter the class late in the semester. This way the students will have multiple class sessions to experience group work with many different students, and make an educated guess as to who they might and might not work well in a group setting with. The students who are always present have a chance to recognise other students who are also always present and possibly could be relied upon. Many students in the focus group interviews expressed the need for more time to form their respective cooperative groups:

'I agree about giving us a little more time in picking our groups. I think a lot of it. I think if you had more time to pick groups, you'd get more people who work responsibility instead of just picking the person next to you.' ... 'They [the instructors] could have told us at the beginning and then in the next three classes we're going to be forming groups to try and get some people lined up on who you want to be with.'

The biggest problem with this scenario is that groups of dependable students would form as well as groups composed entirely of students who are constantly absent. The system of cooperative group learning will then benefit the students who need the least amount of help to begin with, while leaving the students who really need to be attended to by the wayside. 
Another possibility is to form homogenous groups. This also has the advantage of getting students together who potentially work well together, but its disadvantages are numerous. For homogenous cooperative groups to be established correctly requires a tremendous amount of time from the instructors, which is not often available. Homogenous groups also often need to be switched mid-semester for various reasons. The most compelling argument against setting up homogenous groups within a large lecture setting is that it is conflicts with focus group data suggesting that the most effective groups were the familiar groups. With homogenous cooperative groups there is a high potential that most, if not all the groups will be either mixed or random. From the data obtained from the focus groups, this could be detrimental to students' and instructors' objectives.

The optimal number of students in a learning group is also a concern. There is a continual debate among the academic community as to what the best size is for a small cooperative group. Many students in the focus groups indicated that they preferred three people per group rather than four. One student stated:

'I think three would be better cause we have a problem sometimes with what we're doing when the other two are arguing with us two.'

Fortunately many students inadvertently end up with three people in their cooperative group due to habitually absent member. One student said, 'I think all of us pretty much has three people.' Accordingly, forming groups of three in the future might inadvertently form groups of two, or even one.

Another issue still to be addressed is the exact necessity of assigned roles within the cooperative groups. According to the data obtained in the focus groups, the answer is no. The vast majority ignores the roles completely with the exception of the recorder and perhaps the leader. The argument that students provided was that the roles were unnecessary to complete the tasks in a timely fashion:

'In all the work that we do there is not really a need for a skeptic or explorer or whatever they say it is. Lately, it's pretty basic. It's just kind-of obvious and points us in the right direction. So, I don't know. If you were the skeptic or explorer, you'd just sit there all the time. Some people agree no matter how you say it anyway. I mean, we don't have a group skeptic. We don't need to do that. If they don't agree, they say it.'

Other times students stated that an activity may be extremely difficult, and the use of roles would require more time than was available to them. This raises another unresolved question: are assigned roles necessary to obtain efficient and effective small cooperative groups? The results from the focus groups transcripts suggest no, roles are not necessary. However, written surveys conducted at the end of the semester paint a very different picture. Approximately $50 \%$ of the students surveyed either reported using the roles or like having the roles. This discrepancy could happen because of a number of reasons. One reason the surveys were more optimistic in the use of roles within the groups was because the survey was given at the end of the semester. The students might have become more accustomed to the other students in the group and finally felt conformable using the roles. An alternative hypothesis is that the students who participated in the focus groups were informed that the information obtained from the focus groups would be used for future course improvements. For this reason, students were more inclined to voice their opinions in an effort to see the changes this semester. However, in the end-of-term surveys, students might have felt differently.

Overall the focus groups interview provided a tremendous amount of positive feedback. The students were universally adamant about on how well they felt they learned the material, and how this would not have happened within a conventional lecture setting.

\section{Acknowledgments}

This work was funded in part by the Department of Physics of Montana State University and the US National Science Foundation supported 'Science and Engineering for All (SEA) Project' (NSF HRD 9618855). Appreciation is expressed to individuals who helped conduct the focus group interviews: Gina Brissenden, University of Wisconsin at Madison and American Astronomical Society Education Office, Rebecca Lindell-Adrian, University of Nebraska at Lincoln, and Joy Wallace, Science and Math Consortium for Northwest Schools, and Larry Watson, MSU Department of Physics.

\section{References}

Adams, J., \& Slater, T. 1998, Mysteries of the Sky (Dubuque, Iowa: Kendall Hunt Publishing)

Adams, J., Adrian, R., Brissenden, G., Slater, T., \& Wallace, J. 2000, J. College Sci. Teaching, in press

Astwood, P., \& Slater, T. 1997, J. Geoscience Education, 45(3), 238

Cox, C., \& Carpenter, J. 1991, J. Elem. Sci. Education, 1, 14

Dennis, T. R. 1990, The Teaching of Astronomy (Eds H. M. Pasachoff \& J. R. Percy) (Cambridge University Press), p. 101

Duncan, D. 1999, Mercury, 28(1), 14

Fraknoi, A. 1996, Astron Soc. Pacific Conf. Series, Vol. 89 (San Francisco: ASP), p. 9

Francis, G., Adams, J. P., \& Noonan, E. J. 1998, The Phys. Teacher, 36, 488

McDermott, L. 1991, Am. J. Phys., 59, 301

Mazur, E. 1997, Peer Instruction: A User's Manual (New York: Prentice Hall)

Mestre, J. P. 1993, AAPT Announcer, 23(4), 41

Morgan, D. 1988, Focus Groups as Qualitative Research (New Bury Park, Ca: Sage Publications)

Rischbieter, M. O., Ryan, J. M., \& Carpenter, J. R. 1993, J. Geoscience Education, 41, 208

Safko, J. 1988, in The Teaching of Astronomy (Eds H. M. Pasachoff \& J. R. Percy) (Cambridge Univ. Press)

Slater, T. 1997, J. College Science Teaching, 26, 315

Slater, T., \& Astwood, P. 1995, J. Geoscience Education, 43, 216

Slater, T., Carpenter, J., \& Safko, J. 1996, J. Geoscience Education, 44(6), 523 
Slater, T., Hufnagel, B., \& Adams, J. 1999, Proc. AAS Meeting, Chicago

Slavin, R. 1991, Educational Leadership, 48(5), 71

Sokoloff, D. R., \& Thornton, R. K. 1997, The Phys. Teacher, 35, 340

Stewart, D., \& Shamdasani, P. 1990, Focus Groups Theory and Practice (New Bury Park, Ca: Sage Publications)
Wills, M. 1999, A study of collaborative learning group dynamics in an inquiry based physics course. MSc thesis

Zeilik, M. 1997, AAPT Announcer, 26(4), 63

Zeilik, M., Schau, C., Matter, N., Hall, S., Teague, K. W., \& Bisard, W. 1997, Am. J. Phys., 65, 987

Zollman, D. 1990, The Phys. Teacher, 28(1), 20 